\title{
Reflection and Breakthrough on the Dispute Settlement Mechanism of CAFTA
}

\author{
Xue Wang \\ Yunnan University of Finance and Economics, China
}

Keywords: Weak Judiciary; Mediation Mechanism.

\begin{abstract}
CAFTA's Agreement on Dispute Settlement Mechanism is never implemented after signing for more than ten years. The situation of "non-implementation" is worth pondering. This article applies the literature research method to sort out the representative point of view from existing literature. Many scholars believe that the "weak judiciary" in the dispute settlement mechanism of CAFTA is the key problem; the arbitration system should be improved on that basis. This paper holds that, most of these research results are lack of foresight and global views. Under the influence of "the Belt and Road Initiative", the background of regional cooperation has undergone major changes. The only way out for the CAFTA dispute settlement mechanism is to establish and perfect a mediation mechanism.
\end{abstract}

\section{Introduction}

In recent years, trade and investment cooperation between China and ASEAN develops rapidly. In 2015, the volume of trade between China and ASEAN reached 472.1 billion dollars, nearly 60 times of the 7.96 billion US dollars in 1991; the total investment of both sides reached 156.4 billion dollars, more than 300 times of the 500 million dollars in 1991. Disputes are inevitable in trade and investment processes. Most of these disputes are resolved by negotiation, rather than legal means. China and ASEAN Free Trade Area (hereinafter referred to as CAFTA) have signed the Agreement on Dispute Settlement Mechanism for 13 years, but the agreement has not been implemented. The serious deviation between system and practice needs to be discussed carefully.

\section{Existing Viewpoints and Analysis}

The effective operation of dispute settlement mechanism is the foundation for the smooth development of regional economic integration. Therefore, when building CAFTA, the Agreement on Dispute Settlement Mechanism is the first agreement signed under the Framework Agreement. It contains 18 articles and 1 annex, and provides detailed provisions for the scope of application, degree of consultation, mediation and arbitration, as well as the implementation, compensation and suspension of concessions in arbitration. The agreement draws lessons from international principles and are rich in regional characteristics. It is a basic institutional arrangement which relates to the development of this area. However, the Agreement on Dispute Settlement Mechanism of CAFTA has a large number of problems; it is not effectively carried out in practice. In the past decade, many scholars criticized this mechanism.

\subsection{Existing viewpoints}

The CAFTA Agreement on Dispute Settlement Mechanism came into effect in January 1, 2005. It marks the running of CAFTA. Through summarizing, it is found that critical views mainly focus on the "weak judiciary" of this system.

Weak judiciary in procedure. This conclusion is obtained by comparing CAFTA mechanism with WTO and The North American Free Trade Area (hereinafter referred to as NAFTA). The design of CAFTA mechanism is very similar to WTO and NAFTA dispute settlement systems. They all adopt the process of consultation, mediation and adjudication; the biggest difference lies in the different degrees of judicature. The dispute settlement mechanism of WTO is similar to judicial procedure. It 
has strong juridical power over disputes, a permanent dispute settlement agency, and appellate bodies which specialize in analyzing legal issues. It has obvious quasi-judicial features. While the CAFTA mechanism shows a weak judicial tendency.

CAFTA does not establish DSU (Dispute Settlement Understanding) expert group as the entity of adjudication. It adopts the arbitration system. Although NAFTA also adopts arbitration system in dispute settlement mechanism, its arbitration system is more operable.

There is no permanent establishment in CAFTA. WTO has a secretariat and NAFTA has a trade commission.

CAFTA does not have an appellate procedure. WTO has appeals agencies specializing in legal analysis. NAFTA provides a clear dissenting procedure. On one hand, there are special objection procedures for countervailing and anti-dumping matters. On the other hand, experts can be appealed for their obvious misconduct, prejudice and conflicts of interests. This is the shortcoming of CAFTA dispute settlement mechanism.

There are no clear punishment measures in CAFTA. CAFTA only stipulates the suspension of compensation, concession and interest, but there is no specific penalty level. NAFTA stipulates the right to suspend the interest of the other party in the execution procedure.

Poor maneuverability of the arbitration system. Defects in arbitration court. It only stipulates that the chairman should not be the citizen of any party in the dispute; the chairman should not live or work in the dispute country. There are no provisions about other arbitrators.

The arbitration court is a temporary one. Regular investment and trade disputes cannot be resolved timely and effectively.

The voting procedure of arbitration court is flawed. It is inappropriate to give a ruling according to the majority opinion. "Majority" is often difficult to be achieved. The opinion of the chief arbitrator should be the most important factor.

There are no proceedings for revision.

The list of arbitrators is not available; lacks of operability.

In a word, weak judicature is the fundamental characteristic of CAFTA.

\subsection{Comments on existing viewpoints}

Lack of global view. Most of the existing views are lack of global view. Most scholars discuss details and procedures, rather than entities and the whole picture. For example, most researchers discuss the issue of arbitration from perspectives of provisional arbitration court, the composition and voting procedure of the arbitration tribunal, and the execution of arbitral awards. No one analyzes the whole system of the CAFTA dispute settlement mechanism.

Lack of foresight. Why the CAFTA dispute settlement mechanism has so many problems and cannot be implemented? There are two main reasons. First, it is in accordance with the cultural thought of "harmony is the most precious" in Asian countries. The essence of adjudication are confrontation, judgment, regulation and coercion. But Asian countries in the CAFTA region tend to solve disputes in a peaceful and flexible way; they want to avoid confrontation and judgments. Second, it is in line with the contents of economy and trade in CAFTA region. The core issue of CAFTA dispute settlement mechanism is the trade of agricultural products. The program design does not need to be very formal and complex. Arbitration is the main way to solve disputes.

When CAFTA signed the Agreement on Dispute Settlement Mechanism, the dealing of agricultural products was the main form of trade in this region. Thus, arbitration occupies the dominant position in dispute settlement. But now, with the implementation of "the Belt and Road Initiative" strategy, the background of regional cooperation has undergone major changes.

"The Belt and Road Initiative" is the upgraded version of the reform and opening up strategy. Facilities connection is the key cooperation fields of CAFTA, since infrastructure has become the bottleneck which restricts the economic development of ASEAN. Under that background, the informal and simple dispute settlement mechanism which only considers agricultural products trade is not enough. 


\section{Problems in Research Method}

In view of this topic, many scholars use the comparative method and try to modify CAFTA dispute settlement mechanism by comparing it with mechanisms of WTO, NAFTA and EU. It is inappropriate.

CAFTA and WTO do not have comparability. From the form of agreement, the similarity between CAFTA and WTO lies in the value orientation and program design. The dispute settlement, time limit, consultation, mediation and verdict procedure of CAFTA are very similar to the dispute settlement mechanism of WTO. However, the WTO dispute settlement mechanism, DSB, is called "the Pearl on the crown of WTO". It includes consultations, mediation, expert group adjudication, appeal and execution links; its core procedure shows distinct quasi-judicial and "rule orientation" features. The WTO dispute settlement agency, with its expert group and appellate bodies as the carrier, is guided by the treaty law and accepted international laws. It makes the legal system of WTO clearer through the specific interpretation and application of relevant WTO agreements. It is impossible for CAFTA to do that.

CAFTA cannot imitate NAFTA. Compared with CAFTA, NAFTA is also a free trade area dominated by economy and trade. Arbitration is the main way to settle disputes; weak judicature is their common feature. However, their differences are significant. First is the number of people. NAFTA includes only 3 countries, while CAFTA includes 11 countries. Second, their economic structures are different. NAFTA is mainly composed by developed countries, while CAFTA is composed of typical developing countries. Third is the differences in legal system. NAFTA area adopts the typical Anglo-American law system. CAFTA area adopts both Anglo-American law system and continental law system. There are also differences in history, culture and religion. A highly professional arbitration system can be established in NAFTA area for following reasons. First is the high degree of specialization. There are settlement mechanisms for investment dispute between investors and host countries, as well as mechanisms for environment, labor, anti-dumping and countervailing issues. Second is the multiple choices. In addition to professional mechanisms mentioned above, other arbitration rules like DSB and ICSID of WTO can also be selected.

In CAFTA area, there is no clear path. ASEAN countries are all contracting parties of The New York Convention. In theory, the recognition and implementation of adjudication are feasible. But the extents of implementation vary by countries and usually takes a long time. In addition, Vietnam, Thailand and Burma have not yet joined the Washington Convention, so the ICSID arbitration rules cannot be applied. The dispute settlement mechanism needs to seek a new way out.

\section{The Way Out for CAFTA Dispute Settlement Mechanism}

\subsection{Weak judiciary is still the choice of CAFTA region}

It is determined by the humanity and legal environment of this region. When analyzing regional systems, local legal resources should be taken into consideration. As many scholars point out, the humanity and legal environment of Asia is special: the harmonious and moderation culture. The traditional Chinese "no litigation" thought has a profound influence on the development of legal system in China. The weak judicial system aimed at preventing litigation is in line with the traditional thought of "no litigation". The culture is also reflected in Chinese diplomacy principles from the "Five Principles of Peaceful Coexistence" proposed by Premier Zhou, to "putting aside disputes and seeking common development" in South China Sea cooperation during the Xiao-ping Deng period, and to Jin-ping Xi's concept of "amity, sincerity, mutual benefit and inclusiveness" in diplomacy. The design and construction of "the Belt and Road" dispute settlement mechanism requires a fair legal system as the foundation, as well as the culture of harmony and win-win philosophy as the guidance.

It is determined by the deep-rooted influence of the "ASEAN model". The informal and non-mandatory features of ASEAN model also require a weak judiciary system. As Canadian scholar Amitav Acharya expressed, "in the field of dispute settlement, although ASEAN member countries rarely believe in the usefulness and importance of the 'ASEAN Way', its characteristics of avoiding 
formal and legal approaches are deeply rooted." In a word, when dealing with disputes, to avoid legal and rigid rules is more conducive to maintain the unique culture and mainstream values in this region.

\subsection{It is infeasible to reform the existing arbitration system}

Although the weak judicature is still the choice of the CAFTA area, the arbitration procedure is necessary in international and regional trade dispute settlement mechanisms. Its features of equality, efficiency and regularization make the arbitration procedure popular. However, in CAFTA area, it is infeasible to reform the original arbitration system. On one hand, it is well known that commercial arbitrators are concentrated in developed countries. Although CAFTA adopts the "10+1" method, most countries here are developing countries and are lack of international commercial arbitrators. This is why the CAFTA dispute settlement mechanism stipulates that "if the chairman of a special case cannot be determined, the case should be transferred to WTO or international courts". On the other hand, China lacks corresponding leadership. Besides ICC and SCC, as well as international arbitration institutions in Singapore and Hongkong, Chinese arbitral institutions also take many effective measures. According to the China International Economic and Trade Arbitration Report issued by the China Council for the Promotion of International Trade, a considerable number of cases have been dealt with in our country. But compared with world leading arbitration institutions, there is still some way to go.

\subsection{A positive solution for CAFTA dispute settlement mechanism: the establishment of a mediation mechanism}

In recent years, negotiation and diplomacy are the main methods of dispute settling in CAFTA. Compared with mediation, negotiations do not have legitimacy or legal effects. However, compared with negotiation between the two parties of dispute, mediation can not only settle disputes effectively and offer the decisions with justification and legal effects, but also lead both parties in dispute to positive sides. The greatest advantage of mediation is flexible. It can start or stop at any time; there are no strict requirements on the procedure or mediators.

The key is, consultative mechanism of dispute settlement is the development trend in international commercial disputes. With the development of political multi-polarization, economic globalization and cultural diversity, peaceful exchanges, dialogue, mutual benefit and win-win situation will become the common theme of human society. It is the common appeal of mankind to play the role of consultative dispute settlement mechanism in international affairs. In recent years, mediation has become a necessary link in some international economic and trade agreements; mediation procedures have become more substantive and formal. At the same time, international organizations pay increasing attentions on mediation. At the sixty-fourth session of the Working Group II (dispute settlement) of the United Nations Commission on International Trade Law in 2016, participants investigated the enforceability of the settlement agreement of international commercial meditation, planed to establish an international convention which provides compulsory execution effects for settlement (mediation) agreements reached by the international commercial mediation organization. This shows that reconciliation and mediation have become the international trend.

To sum up, the mediation mechanism should be given full play to improve the CAFTA dispute settlement mechanism. The mediation mechanism can balance gaps in economic strength, resources, legal technology and rules of the 10+1 countries, avoid political and ideological problems in a flexible way, maximize the interests of parties and keep the order of the free trade area. It also helps governments of all countries to combine their political wisdom with folk ways, so as to solve problems in administrative management, to control differences and deal with the relationship between righteousness and interests, and maintain friendship with other member countries.

\section{References}

[1] L.Y. Yang, Study on the Legal System of Regional Economic Integration, Law Press of China, Beijing, 2004. 
[2] A. Acharya, Constructing a Security Community in Southeast Asia: ASEAN and the Problem of Regional Order, Z.Y. Wang, H.X. Feng (Trans.), Shanghai Century Publishing Group, Shanghai, 2004.

[3] S.B. Shen, On the Agreement on Dispute Settlement Mechanism of the Framework Agreement on Comprehensive Economic Cooperation Between the People's Republic of China and the Association of Southeast Asian Nations, J. Journal of Shanghai University of Finance and Economics.1 (2006).

[4] Y. Fan, The internationalization trend of diversified dispute settlement mechanisms, People's Court Daily, July 6, 2016.

[5] X.X. Song, P. Wu, On the Agreement on Dispute Settlement Mechanism of the Framework Agreement on Comprehensive Economic Cooperation Between the People's Republic of China and the Association of Southeast Asian Nations and its improvement, J. Presentday Law Science. 5 (2006). 